\title{
Awareness and practice of computer-related ergonomics among
}

\section{resident doctors}

\author{
Abu Saleh Mohammad Mainul Hasan, Abul Khair Mohammad Salek and Syed Mozaffar Ahmed
}

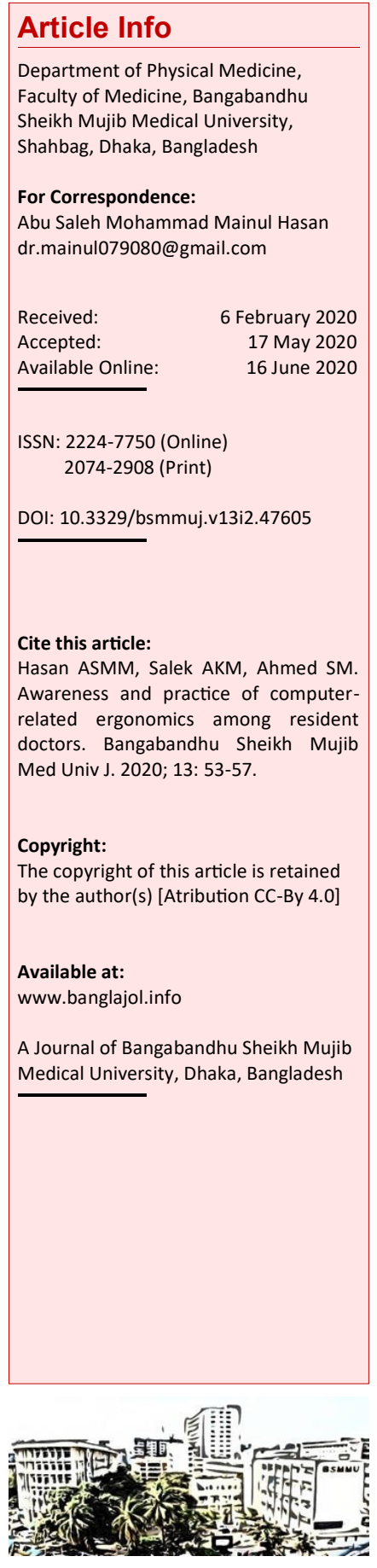

\section{Abstract}

The present study was designed to see the level of awareness and practice of computer-related ergonomics among resident doctors. A total of 227 residents participated in this study who had used a computer for at least a year. They were selected by simple random sampling. A selfreporting questionnaire was used to conduct the study. For better understanding and convenience, the responses were categorized into good, fair, and poor. Awareness level was good in only 15\% $(n=34)$ of residents, fair in $16.7 \%$ and the majority $68.3 \%(n=155)$ of residents had a poor level of awareness about ergonomics. Poor computer ergonomics was practiced by $49.5 \%$ of residents, while fare and good practice of computer ergonomics were found in $24.2 \%$ and $26 \%$ of residents respectively. The formal training program on computer ergonomics was unattended by $93.5 \%$ of participant residents. In graduation/postgraduation level $81.5 \%$ of residents didn't get any lecture on correct posture. To measure the practice of computer ergonomics, we found that $64.3 \%$ of residents didn't take breaks regularly while using a computer, $69.2 \%$ didn't use an adjustable chair and $59 \%$ didn't have armrests in those chairs. Proper positioning of knee, elbow, and wrist during computer use wasn't maintained by $56.8 \%, 58.1 \%$, and $44.9 \%$ of residents respectively. A significant association was found between awareness and resident phase with computer practice $(\mathrm{p}<0.005)$ and sex with awareness $(\mathrm{p}<0.005)$.

\section{Introduction}

Computers have become an integral part of our modern life. The use of the computer and the internet is rapidly becoming a key component of both the medical education and professional life of physicians in many parts of the world. Physicians use computers for a variety of purposes like accessing professional resources, searching information, clinical note-taking, to keep electronic health records (EHR), e-prescribing, communication among colleagues and administrative tasks.., 2 Easy access to digital information and communication have revolutionized computer uses in the medical profession in Bangladesh also. A study among 322 medical students in a medical college in Dhaka showed that $66.8 \%$ had personal computers. 3 Since 2009 the MIS unit of the Directorate General of Health Services of Bangladesh has equipped almost every public sector health facility in the country with computers and internet connections. $\underline{4}$

The word ergonomics is derived from Greek words, "ergo" and "nomos", meaning work and law respectively. $\underline{5}$ Ergonomics has been described as the science that deals with adjusting any work environment, tools, task, and equip- ment to fit with the person's physical capability and limitations to provide a safe, comfortable environment and reduce the risk of the workrelated injury. $.6,7$ Ergonomics emerges as an important issue in case of computer use because, in the absence of good ergonomic design, computer work for prolonged periods in faulty posture can adversely affect vision, muscles of the neck, upper back, shoulders, and arms, leading to visual and muscular fatigue and pain. .8 Hedge and James (2014) in a survey among 204 health professionals found that electronic health record (EHR) implementation had substantially increased daily computer use in $90 \%$ of health professionals and around twothirds of them reported increased frequency of neck, shoulder back and wrist discomfort because of not considering computer ergonomics while using computer. .9

Ergonomics training and intervention is frequently cited as the best way to reduce the incidence of computer-related health disorders. 10,11 So, there is a need to educate new computer users about computer-related ergonomics. $\underline{12}$ But the results of different studies show that many people are not aware of ergonomics and they fail to put it into 
practice. Only $25.5 \%$ in Nigeria and $28.7 \%$ in Pakistan in the medical profession were seen to be aware of ergonomics $\underline{13,14}$ Unfortunately, to date there is no data available on this topic among the physician community of Bangladesh. Among all physicians, resident doctors have an incomparable position because they have to play a dual role of being a clinician and a student at the same time. $\underline{15}$ In this context, the present study was designed to see the level of awareness regarding computer ergonomics and the pattern of practice of computer ergonomics among resident doctors.

\section{Materials and Methods}

The study was performed from March 2015 to September 2016 among the 227 resident doctors (142 males, 85 females; age range 26-42 years) of Phase-A $(n=103)$ and Phase-B $(n=124)$ of three faculties who used desktop/laptop computer for at least one year. Two hundred were Bangladeshi and the rest of them were foreign residents. Residents were selected irrespective of age, sex, and nationality by

\begin{tabular}{|c|c|c|}
\hline \multicolumn{3}{|c|}{ Table I } \\
\hline \multicolumn{3}{|c|}{ Awareness of computer ergonomics $(n=227)$} \\
\hline Variable & Response & Frequency \\
\hline \multirow[t]{2}{*}{ Heard the term 'Ergonomics' } & No & 144 \\
\hline & Yes & 83 \\
\hline \multirow{5}{*}{$\begin{array}{l}\text { Knowledge about computer ergo- } \\
\text { nomics }\end{array}$} & Poor & 89 \\
\hline & Little/Not satisfactory & 97 \\
\hline & Satisfactory & 32 \\
\hline & Good & 8 \\
\hline & Excellent & 1 \\
\hline \multirow{4}{*}{$\begin{array}{l}\text { Lecture/session in graduation/ } \\
\text { post-graduation level on correct } \\
\text { posture } \\
\text { Formal training program on com- } \\
\text { puter ergonomics }\end{array}$} & No & 185 \\
\hline & Yes & 42 \\
\hline & No & 212 \\
\hline & Yes & 15 \\
\hline \multirow[t]{4}{*}{ Learn about computer ergonomics } & I didn't learn it & 119 \\
\hline & Read documents on it & 87 \\
\hline & $\begin{array}{l}\text { Attended an educa- } \\
\text { tional training pro- } \\
\text { gram (lecture/course) }\end{array}$ & 14 \\
\hline & Both & 7 \\
\hline
\end{tabular}

simple random sampling calculated using Cochran's (1977) sample size formula for a sufficiently large population. Residents who had any physical disability which prevented him/her from practicing computer ergonomics, who had a history of fractures or major trauma, inflammatory rheumatic diseases like rheumatoid arthritis, spondyloarthropathy and any systemic illness were excluded from this study.

A structured, close-ended, investigator-developed, self-reporting questionnaire was used to conduct the study. The questionnaire was prepared based on previous studies on ergonomics, theory, a standard questionnaire on computer ergonomics (Easy ergonomics: For desktop computer users, 2005). $., 14,16$ -18 The questionnaire was divided into three segments: general information about participant residents, awareness of computer ergonomics, and practice of computer ergonomics. In the study, the level of awareness and practice of computer ergonomics were judged by categorizing awareness and practice of ergonomics into 3 categories: good, fair, and poor. Resident doctors answered some questions in the individual section on the awareness and practice of computer ergonomics. Answering a section resulted in some scoring points according to the Likert scale. Then summation of these scores culminated in a category (Good/fair/poor) of that section. $\underline{19,20}$

All the data were compiled and sorted properly and the data were analyzed statistically by using Statistical Package for Social Sciences (Version20). The Chi-square test was used to determine the association between categorical variables and computer-related variables with awareness and practice of study participants.

\section{Results}

\section{Awareness of computer ergonomics}

Analyzing Table I, it was observed that $63.4 \%$ (144 residents out of 227) of the total respondents had not heard the term ergonomics and only 36.6\% heard the term. The majority of the resident i.e, $42.7 \% \quad(n=97)$ claimed that their knowledge about computer ergonomics was little/not satisfactory and $39.2 \% \quad(n=89)$ rated it as poor and only 1 resident rated it as excellent. $81.5 \% \quad(n=185)$ of residents said that they did not get or attend any lecture on correct posture in their MBBS life or at the postgraduation level. Only $6.6 \%$ of residents attended formal training programs on computer ergonomics and $38.3 \%(n=87)$ had read a document on computer ergonomics on the internet or paper.

\section{The practice of computer-related ergonomics}

Analyzing Table II, we found that majority of residents didn't follow the parameters of good ergonomic use of a computer. $64.3 \%(n=146)$ of respondents didn't regularly take breaks every 20 30 minutes while using the computer. Only 43.2\% $(n=98)$ could keep thighs parallel to the floor with hip and knee at 90 degrees. $69.2 \%(n=157)$ of them 
Table II

\section{Practice of computer ergonomics $(n=227)$}

\begin{tabular}{|lcc|}
\hline Variable & Response & Frequency \\
\hline Regularly take a break every 20- & No, use it continuously & 146 \\
30 min & Yes & 81 \\
Thighs parallel to the floor with & No & 129 \\
hip and knee at $90^{\circ}$ & Yes & 98 \\
The curve of the chair fit into & No & 157 \\
the lower back & Yes & 70 \\
Can work without overreach- & No & 57 \\
ing/awkward posture & Yes & 170 \\
Document off the flat work & No & 179 \\
surface and at the same distance & Yes \\
as the monitor & No & 48 \\
The chair has an armrest & Yes & 134 \\
& No & 93 \\
Elbows bent to 90 degrees and & Yes & 132 \\
close to the body & No & 95 \\
keyboard at the same height as & Yes & 116 \\
elbow & No & 111 \\
Wrist straight during keying & Yes & 102 \\
(not bent) & No & 125 \\
The shoulder remains relaxed & Yes & 71 \\
(not hunched) & No & 156 \\
A monitor placed at a comforta- & Yes & 73 \\
ble distance (50-100 cm) & No & 154 \\
Top of the screen at or below & Yes \\
eye level & & 67 \\
\hline
\end{tabular}

didn't have a chair with a curve that fits the lordotic curve of the lower back. 59\% $(n=134)$ didn't have chairs with armrest. $58.1 \%(n=132)$ didn't keep elbow bent to 90 degree and close to the body.51.1\% $(n=116)$ didn't use the keyboard at the same height

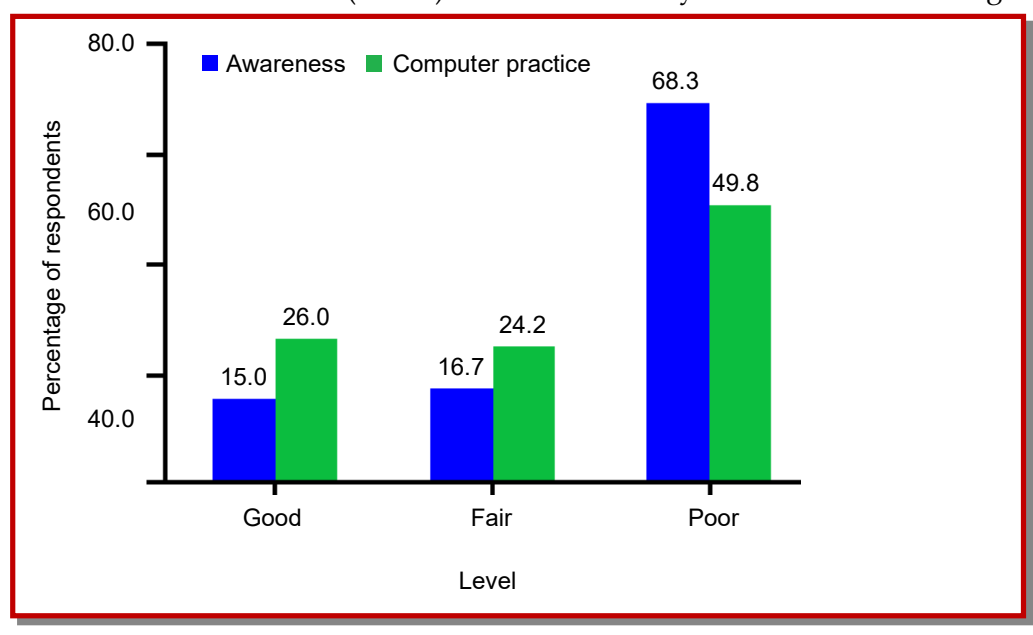

Figure 1: Level of awareness and practice of computer ergonomics as the elbow. In the case of viewing the monitor, the parameters were better. $70.5 \% \quad(n=160)$ used a computer monitor in such height that the top of the screen was at or just below the eye level and they could read the monitor screen with only eye movements, not head movements. $67.8 \% \quad(n=154)$ viewed the monitor at a comfortable distance.

\section{Level of awareness and practice of computer ergonomics}

Figure 1 illustrates the overall picture of the categorization of residents by awareness and practice of computer-related ergonomics. Awareness level was good in only $15 \% \quad(n=34)$ of residents, fair only in $16.7 \%$ of residents and the majority $68.3 \% \quad(n=155)$ of residents had poor awareness of ergonomics. $49.5 \% \quad(n=113)$ of participant residents practiced poor computer ergonomics while using their computers. $24.2 \%$ $(n=55)$ of them did fair practice and $26 \%(n=59)$ did good practice of computer ergonomics. It was observed that poor awareness was higher than other ratings of awareness in all the age groups especially in older age groups than the younger ones. A significant association of sex with awareness $\left(\chi^{2}=7.030, p=0.030\right)$, residents phase with practice $\left(\chi^{2}=9.871, \mathrm{p}=0.007\right)$ and computer practice with awareness $\left(\chi^{2}=18.762\right.$, $p=0.001)$ was observed as a $5 \%$ level of significance. We didn't see much of a difference phase -wise or faculty wise, though residents of PhaseA and surgery faculty had slightly better awareness category wise than their counterparts.

\section{Discussion}

This study revealed that the majority of residents had an unsatisfactory and poor level of awareness about computer ergonomics and didn't follow the parameters of good ergonomic use of a computer. The reason behind this finding was the lack of any lecture and training on computer ergonomics and correct body posture in MBBS and postgraduation level. This reason had been backed up by two previous studies. $.21,22$

In this study, $144(63.4 \%)$ residents even hadn't heard the term ergonomics. This scenario is slightly better than Sarfraz et al. (2013), Oladeinde et al. (2015), and Ismaila (2010) and worse than Khan et al. (2012).6,8,13,14 But those studies didn't specifically measure the level of awareness. Shantakumari et al. (2012), said that $44 \%$ of their study samples were aware of ergonomics. $\underline{16}$ But here any specific measurement tool for measuring awareness could not be found. In this study, a rating scale was used to measure and categorize the level of awareness based on some previous studies. 19,20 In this study, $68.3 \%$ of residents had poor awareness and only 
$15 \%$ had good and $16.7 \%$ had fare awareness level. Kalghatgi et al. (2014) found fair knowledge of ergonomics among $57.2 \%$ while Siddiqui et al. (2016) found fare knowledge among $38.4 \%$ and good among $21.4 \%$ of dentists. 19,23 So, in comparison to other studies, our residents had an inferior level of awareness about ergonomics. This just reflects the lack of education about ergonomics in our education system.

Ergonomic intervention and training about computer ergonomics increases knowledge and awareness about it and decreases the frequency of computer-related musculoskeletal disorders.24, 25 Only $6.6 \%$ of residents of this study attended a formal educational training program on computer ergono-mics in comparison to $37.67 \%$ found by Sarfraz et al. (2013)14 38.3\% of residents in this study had read documents on computer ergonomics, whereas it was $22.9 \%$ in another study. .16

In this study, $64.3 \%(n=146)$ of respondents didn't take a break every 20-30 min when using a computer. Prolonged sitting or standing without breaks or rest increases intradiscal load and weakens posterior lumbar structures. $25.1 \%(n=57)$ of residents had to adopt awkward posture during computer use. A long duration of improper posture contributed to repetitive injuries of the lower and upper back. $\underline{26}$

Other workplace modifications during computer use include the use of an adjustable chair to prevent neck and upper thoracic strain and provision of forearm rest in the chair to support the arms, forearm, and elbow. In this study, most of the residents didn't have an adjustable chair in contrast to another study done among bankers in Dhaka. 27 59\% $(n=134)$ of these chairs didn't have armrest, almost similar finding to Khan et al (2012) who found that only $20 \%$ of their respondents used armrest. $856.8 \%(n=129)$ of residents can't keep thigh parallel to the floor and hip and knee at 90 degrees to each other. This type of posture also puts a strain on the lower back and knees. 27,28 Posture correction is an important factor to reduce low back pain. $\underline{29}$ $69.2 \%(n=157)$ didn't have a chair which has a curve that fits the lordotic curve of the lower back, so by using these type of chairs residents didn't get upper and lower back support. As most of the residents didn't have an ergonomic chair, most of them (58.1\%) couldn't keep their elbows bent to 90 degrees and close to the body. $44.9 \%$ of residents kept their wrist bent, not straight during keying and 51.1\% didn't use a keyboard at the same height as the elbow. These findings of computer practice were worse than that of UAE study. 16 Overall, $49.5 \%$ of residents fell into the category of the poor practice of computer ergonomics, $26 \%$ was a good practitioner and $24.2 \%$ was a fair practitioner of computer ergonomics.

\section{Conclusion}

Most of the resident doctors had poor awareness of computer-related ergonomics. The majority of them didn't get any formal education on computer ergonomics and as a consequence, they didn't practice ideal ergonomics in front of a computer.

\section{Funding Sources}

Self-funded

\section{Ethical Issue}

Before starting the study, approval was taken from the Ethical Committee (Institutional Review Board, IRB) of BSMMU (BSMMU/2015/13162). All precautions were taken to protect privacy, anonymity, and confidentiality of the information given by the participant residents. Participants enjoyed the fullright to withdraw themselves from the study at any time for any reason what-so-ever. A well informed written consent was obtained from the subject.

\section{Conflict of Interest}

The authors declare no conflict of interest.

\section{Acknowledgement}

We are grateful to all those residents for their kind cooperation.

\section{References}

1. Unnikrishnan B, Kulshrestha V, Saraf A, Agrahari AC, Prakash S, Samantaray L, Parida A. Pattern of computer and internet use among medical students in Coastal South India. Southeast Asian J Med Educ. 2008; 2: 18-25.

2. Epocrates. Epocrates 2013 Mobile Trends Report: Maximizing multi-screen engagement among clinicians, 2013

3. Chowdhury NS, Chowdhury NN, Rabbi F, Tabassum R, Ishrat S. Computer literacy and attitudes towards e-learning among Bangladeshi Medical Students. Update Den Col J. 2013; 3: 3-6.

4. GIZ A. Quiet revolution strengthening the routine health information system in Bangladesh. JLN 
Web. 2014.

5. Ball MJ, JA EM. Introduction to nursing informatics. New York, Springer, 2006.

6. Ismaila SO. A study on ergonomics awareness in Nigeria. Aust J Basic Appl Sci. 2010; 4: 731-34.

7. Karibasappa GN, Sujatha A, Rajeshwari K. Dentists' knowledge, attitude and behavior towards the dental ergonomics. IOSR J Dent Med Sci. 2014; 13: 86-89.

8. Khan R, Surti A, Rehman R, Ali U. Knowledge and practices of ergonomics in computer users. J Pakistan Med Assoc. 2012; 62: 213.

9. Hedge A, James T. Detrimental effects of an electronic health record system on musculoskeletal symptoms among health professionals. Proc Hum Factors Ergon Soc Annu Meet. 2014; 58: 773-77.

10. Jacobs K, Johnson P, Dennerlein J, Peterson D, Kaufman J, Gold J, Williams S, Richmond N, Karban S, Firn E, Ansong E. University students' notebook computer use. Appl Ergon. 2009; 40: 404-09.

11. Mahmud N, Kenny DT, Zein RM, Hassan SN. Ergonomic training reduces musculoskeletal disorders among office workers: Results from the 6month follow-up. Malays J Med Sci. 2011; 18: 16.

12. Smith L, Louw Q, Crous L, Grimmer-Somers K. Prevalence of neck pain and headaches: Impact of computer use and other associative factors. Cephalalgia 2009; 29: 250-57.

13. Oladeinde BH, Ekejindu IM, Omoregie R, Aguh OD. Awareness and knowledge of ergonomics among medical laboratory scientists in Nigeria. Ann Med Health Sci Res. 2015; 5: 423-27.

14. Sarfraz M, Kashmala FS, Anees S. Awareness of ergonomics among the physiotherapy and medical students. Pakistan J Rehab. 2013; 2: 31-37.

15. McCray LW, Cronholm PF, Bogner HR, Gallo JJ, Neill RA. Resident physician burnout: Is there hope? Fam Med. 2008; 40: 626.

16. Shantakumari N, Eldeeb RA, Sreedharan J, Gopal $\mathrm{K}$. Awareness and practice of computer ergonomics among university students. Int J Med Health Sci. 2012; 1: 15-20.

17. Abul-Qasim J, Hadi S, al-Saleh M, Abu-Alkhair M, Sutaih M, Karaly AA. Arthralgia in computer users in Almadinah Almunawwarah, Kingdom of Saudi Arabia. J Taibah Univ Med Sci. 2014; 9: 250-55.

18. Mehrdad R, Morshedizadeh M. Musculoskeletal disorders and ergonomic hazards among Iranian physicians. Arch Iranian Med. 2012; 15: 370.
19. Kalghatgi S, Prasad KV, Chhabra KG, Deolia S, Chhabra C. Insights into ergonomics among dental professionals of a dental institute and private practitioners in Hubli-Dharwad twin cities, India. Saf Health Work. 2014; 5: 181-85.

20. Zakerian SA, Monazzam MR, Dehghan SF, Mohraz MH, Safari H, Asghari M. Relationship between knowledge of ergonomics and workplace conditions with musculoskeletal disorders among nurses: A questionnaire survey. World Appl Sci J. 2013; 24: 227-33.

21. Robertson MM, Amick III BC, Hupert N, PellerinDionne M, Cha E, Katz JN. Effects of a participatory ergonomics intervention computer workshop for university students: A pilot intervention to prevent disability in tomorrow's workers. Work 2002; 18: 305-14.

22. Jacobs K, Johnson P, Dennerlein J, Peterson D, Kaufman J, Gold J, Williams S, Richmond N, Karban S, Firn E, Ansong E. University students' notebook computer use. App Ergo. 2009; 40: 404-09.

23. Siddiqui TM, Wali A, Khan OH, Khan M, Zafar F. Assessment of knowledge, practice, and work environment related to ergonomics among dental students and dental practitioners. Int J Contemp Dent Med Rev. 2016.

24. Bowman PJ, Braswell KD, Cohen JR, Funke JL, Landon HL, Martinez PI, Mossbarger JN. Benefits of laptop computer ergonomics education to graduate students. Open J Therap Rehab. 2014; 2: $25-32$.

25. Ketola R, Toivonen R, Häkkänen M, Luukkonen R, Takala EP, Viikari-Juntura E. Effects of ergonomic intervention in work with video display units. Scand J Work Env Health. 2002; 28: 18-24.

26. Khan MY, Siddiqui MA. Prevalence of low back pain in computer users. Pakistan Med Sci Q. 2005; 21: 159-63.

27. Emran M, Ahmed SM, Hasan MI, Emran A. Occupation-related physical activities in osteoarthritis of the knee in female. Bangabandhu Sheikh Mujib Med Univ J. 2019; 12: 84-87.

28. Amin MR, Hossain SM, Eusufzai SZ, Barua SK, Jamayet NB. The prevalence of computer related musculoskeletal disorders among bankers of Dhaka city. Chatt Maa-O-Shi Hosp Med Col J. 2016; 15: 4044.

29. Shakoor MA, Islam MT, Salek AK, Moyeenuzzaman M. Effects of rehabilitation on the patients with chronic low back pain. Bangabandhu Sheikh Mujib Med Univ J. 2019; 12: 6-9. 